\title{
Nächtlicher Vorphall
}

\section{Bernhard Gurtner}

Korrespondenz:

Dr. med. Bernhard Gurtner

Eggstrasse 76

CH-8620 Wetzikon

gurtner.bernhard@bluewin.ch
War das ein Tumult gestern abend im Zimmer 306 auf der Chirurgie. Der verunfallte Bauarbeiter wollte einfach nicht begreifen, dass es mit frisch operierten Arm- und Beinbrüchen nicht möglich ist, auf die Toilette zu gehen. Die Spätdienst leistende deutsche Pflegefachfrau verstand weder sein mit Schwyzerdütsch vermischtes Italienisch noch seine heftige Abwehr der Urinflasche, die sie ihm zustecken wollte. Seinen «cazzo» werde keine fremde Frau sehen oder gar berühren dürfen, das habe er seiner «moglie» hochheilig versprochen. Da konnte Monika aus Erfurt noch so beteuern, dass sie sich durch den professionellen Anblick eines Penis keinesfalls beeindrucken oder gar verführen liesse, der hitzige Sizilianer verweigerte stur jeden Zugriff, geriet aber immer mehr unter Druck seiner überfüllten Blase und zappelte mit dem gesunden Bein grobschlägig unter der Bettdecke.

Die drei Zimmergenossen redeten dem Uneinsichtigen zu, gebrauchten umsorgend das kindische Wort «Pipimachen», um ihn zu ermuntern, seinen Schwanz in die Flasche stecken zu lassen mit den fixierten Armen konnte er es nicht selbst tun, und auch diese umliegenden Männer vermochten ihm nicht zu helfen, weil sie alle mit Infusionsschläuchen und Kathetern ans Bett gefesselt waren. Die genervte Monika schlug schliesslich vor, die Frau des Patienten zu bitten, den Ehemann notfallmässig von dem Gelübde zu entbinden, um 22.30 Uhr dürfe man schon noch anrufen. Doch wusste der Verklemmte in der Aufregung nicht einmal die eigene Telefonnummer, die aber dank vereinigtem Know-how in seinem Handyspeicher doch noch gefunden wurde. Nach einem kurzen, drangvollen Gestammel erreichte der Jammernde überraschend schnell die Zustimmung seiner besorgten Gattin, worauf er mit viel Grandezza sein Prachtstück entblösste und die Urinflasche andocken liess, die er mit kräftigem Strahl bedrohlich rasch anfüllte.

Die Erklärung für das merkwürdige Verhalten des Südländers kam heute morgen: Die Laborantin hatte sich gestern bei der Blutabnahme versehentlich gestochen. Nun wollte sie die Einwilligung des Patienten für einen HIV-Test. «Keine Angst, Signora, mein Test war vor einer Woche ganz prima», erklärte der Patient stolz und gestand ebenso freimütig, dass er kürzlich in den Badeferien den Reizen einer wunderbaren Inselschönheit erlegen sei. Seine Frau habe das fremde Parfum gerochen, eine grosse Szene gemacht, mit sofortiger Abreise und Scheidung gedroht und sich erst wieder beruhigt, als er einen HIV-Test unbefleckt bestanden hatte und bei allen zuständigen Heiligen schwor, niemals mehr einer anderen Frau seinen «pene» zu zeigen. Dieses Eheversprechen wollte er nicht noch einmal brechen, auch nicht im Spital vor einer jungen deutschen Krankenschwester.

Wow, haben die im Männersaal 306 gelacht, einige frische Operationsnähte drohten zu platzen. Und alle sind jetzt gespannt auf den ersten Besuch der betrogenen und dennoch so grossmütig verzeihenden «sposa» am Bett ihres Pipi Gipsstrumpf. 